\title{
Comparative study on the deterioration of granite under microwave irradiation and resistance-heating treatment
}

\author{
Qijun $\mathrm{Hu}$, Zihe Shou, Junsen Zeng \\ School of Civil Engineering and Architecture, Southwest Petroleum University, Chengdu 610500, China \\ buqijunswpu@163.com,1025533017@qq.com,845491134@qq.com
}

\section{Leping He}

State Key Laboratory of Oil and Gas Geology and Exploitation, Chengdu 610500, China

201231010028@swpu.edu.cn

\section{Hexi Tang}

Fundamental Science on Nuclear W astes and Environmental Safety Laboratory, Southwest University of Science and Tecbnology, Mianyang 621010, China

280261252@qq.co

\section{Bingsheng Li}

State Key Laboratory of Environmental-friendly Energy Materials, Southwest University of Science and Technology, Mianyang 621010, China

893067326@qq.com

\section{Shunzhang Chen}

Fundamental Science on Nuclear W astes and Environmental Safety Laboratory, Southwest University of Science and Technology, Mianyang 621010, China

mr_chen1993@foxmail.com

Xirui $\mathrm{Lu}$

State Key Laboratory of Environmental-friendly Energy Materials, Southwest University of Science and Technology, Mianyang 621010, China

luxiruimpp116@163.com

ABSTRACT. To investigate the deterioration of granite under microwave irradiation and heat transfer, granite specimens were heated up to 400-1000 ${ }^{\circ} \mathrm{C}$ and then kept for $15 \mathrm{~min}$. Uniaxial compressive strength testing results demonstrate a similar variation in two groups in $400-900{ }^{\circ} \mathrm{C}$, which is initial strengthening (less than $500^{\circ} \mathrm{C}$ ), subsequent weakening $\left(500-600^{\circ} \mathrm{C}\right)$ and final stabilizing $\left(600-900^{\circ} \mathrm{C}\right)$. Furthermore, the specimen irradiated by microwaves

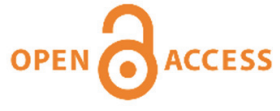

Citation: Hu, Q., Shou, Z., Zeng, J., He, L., Tang, H., Li, B.,Chen, S., Lu., X., Comparative study on the deterioration of granite under microwave irradiation and resistance-heating 
presented a second decline at $1000^{\circ} \mathrm{C}$. Compared to heat transfer, microwave irradiation can reduce the strengthening due to localized transition plasticity and further promotes the deterioration of rock structure in weakening stage. TG/DSC results indicate that the strengthening is related to the iron mineral transition. The formation of porous glass substance which is mainly composed of feldspar and biotite. Furthermore, temperature-controlled microwave irradiation induced the variation of feldspar FWHM, which is consistent with the corresponding UCS data, especially the plagioclase. In practical application, microwaves can be used to irradiate the vulnerable positions (surface edge and cleavage) and kept the whole rock mass around $600{ }^{\circ} \mathrm{C}$.

KEYWORDS. Granite; Thermal damage; Microwave irradiation; Heat transfer treatment, Frattura ed Integrità Strutturale, 50 (2019) 638-648.

Received: 15.03 .2019

Accepted: 02.09.2019

Published: 01.10.2019

Copyright: (C) 2019 This is an open access article under the terms of the CC-BY 4.0, which permits unrestricted use, distribution, and reproduction in any medium, provided the original author and source are credited.

\section{INTRODUCTION}

$\mathrm{I}$ $\mathrm{n}$ recent years, due to the demand of deep geological applications, microwave-assisting mechanical method is profoundly discussed for more efficient excavation and lower energy consumption $[1,2,3]$. It means that rock is preirradiated by microwaves and subsequently excavated by mechanical tools. Actually, only a part of rock is concentrated exposed to microwave irradiation in practical application, so called the directly irradiated zone [4,5]. Artificially cracks within the directly irradiated zone are induced to weaken the integrity of rock structure and reduce the level of excavation tools wear and maintenance. However, most of internal rocks are indirectly heated by the irradiated zone through heat transfer instead of directly irradiated by microwaves. Subjected to the different heating mechanisms, the damage of whole rock mass is apparently heterogeneous. Investigating the deterioration of rock mass under the two conditions can prevent the serious accident due to hastily excavation.

Rocks responding to microwave irradiation relies on the rock-forming minerals absorbing the electromagnetic energy and converting into heat energy [6,7]. Rock-forming minerals exist different heating rates due to the otherness of dielectric properties $[8,9,10]$. Lu [10] further identified that most rock-forming minerals were weak microwave absorbers, e.g. quartz and feldspar, and the good microwave absorption of enstatite and biotite were linked to the contribution of ferrum. Consequently, thermal gradient appeared and leaded to selective cracking along the boundaries of good microwave absorbers [11,12,13]. In addition, both high microwave power level and long exposure time can induce the higher temperature and more serious damage by generating more heat $[5,14]$.

Researchers normally employed resistance-heating furnace to simulate the rock at different high temperature conditions. Yang [15] declared that the failure mechanism of granite over $400{ }^{\circ} \mathrm{C}$ was attributed to the coalescence of intergranular and transgranular cracks in feldspar and quartz gains. Zhang [16] and Zhang [17] found that $200{ }^{\circ} \mathrm{C}$ and $500{ }^{\circ} \mathrm{C}$ were the temperature thresholds of the limestone microstructure deterioration. Sirdesai [18] demonstrated that the phase transition of quartz induced the sharply decrease of sandstone mechanical performances over $573{ }^{\circ} \mathrm{C}$. Besides, mineral dehydration as temperature increased were also declared to weaken the rock structure [19-22].

Almost all literatures mentioned the deterioration of rock with temperature increasing is significantly related to the crystal mineral characteristics' changing at specific temperatures induced by either microwave irradiation or heat transfer. Granite is one of most common hard rock in underground excavation. The deterioration of granite in a broad range of temperature by using resistance-heating treatments have been widely investigated. However, there are few references considering the structural deterioration difference of granite for the temperature greater than $400{ }^{\circ} \mathrm{C}$ exposed to microwave irradiation and heat transfer.

This study will qualitatively describe the difference of granite structural deterioration over $400{ }^{\circ} \mathrm{C}$ treated by microwave irradiation and heat transfer on the basis of mineralogical variation and furthermore assess the appropriate irradiating condition in practical engineering applications. Therefore, the uniaxial compressive strength (UCS) testing was employed in order to obtain the forces acquired for destroying the specimens, and the thermogravimetric/differential scanning calorimetry analysis (TG/DSC), Scanning electronic microscope (SEM) and X-ray diffraction (XRD) were used for characterizing the variation of crystal minerals in granite. 


\section{MATERIALS AND METHODS}

\section{Granite description}

7 he candidate granite was collected from Danfeng in Shanxi province, China. Petrographic thin section was prepared and observed by optical polarizing microscopy (Leitz Laborlux 12 pol, Germany), as shown in Fig. 1. The mineralogical composition for Danfeng granite is: $64 \%$ feldspar (54\% K-feldspar and $10 \%$ plagioclase), $30 \%$ quartz and $6 \%$ biotite. Auxiliary minerals including magnetite and apatite are also found. The grain size of single mineral ranges from about $0.3 \mathrm{~mm}$ to $3.5 \mathrm{~mm}$. Besides, partial graphic and vermicular textures can be also observed. X-ray fluorescence (XRF, PANalytical, B.V. Axios) was also employed to obtain the composition of granite, as listed in Tab. 1. The mean value of UCS for the granite at room temperature is $101.84 \mathrm{MPa}$.

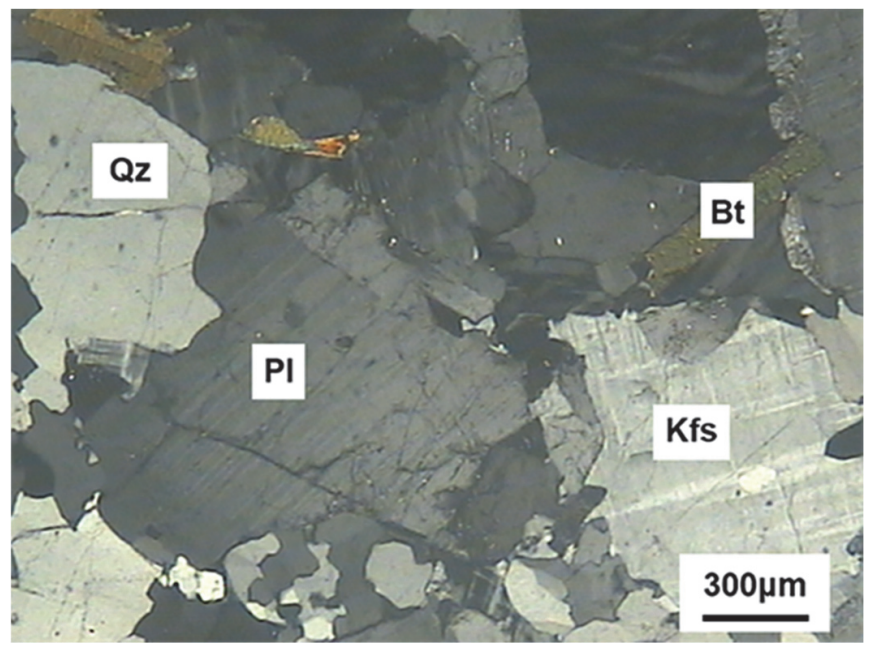

Figure 1: Petrographic thin microscopy image of the granite (Kfs-potash feldspar; Pl-plagioclase; Qz-quartz; Bt-biotite).

\begin{tabular}{ccccccc}
\hline Oxide & $\mathrm{SiO}_{2}$ & $\mathrm{Al}_{2} \mathrm{O}_{3}$ & $\mathrm{~K}_{2} \mathrm{O}$ & $\mathrm{CaO}$ & $\mathrm{Fe}_{2} \mathrm{O}_{3}$ & $\mathrm{Na}_{2} \mathrm{O}$ \\
Content $/$ wt. $\%$ & 75.90 & 14.87 & 4.05 & 2.57 & 1.34 & 0.48 \\
\hline
\end{tabular}

Table 1: Composition of Danfeng granite.

\section{Heating treatments}

The two heating conditions were performed with a $1.5 \mathrm{~kW}$ microwave oven with a frequency of 2.45 GHz (HAMiLabM1500, SYNOTHERM) and a 12 kW muffle furnace (KSS-1700, Xiangtan Sanxing Instrument Co., Ltd), respectively. For a simplified description, microwave irradiation group was named group $\mathrm{A}$ and the resistance-heating group was named group B. Specimens were heated up to set temperatures $\left(400^{\circ} \mathrm{C}, 500{ }^{\circ} \mathrm{C}, 600{ }^{\circ} \mathrm{C}, 700{ }^{\circ} \mathrm{C}, 800{ }^{\circ} \mathrm{C}, 900{ }^{\circ} \mathrm{C}\right.$ and $\left.1000{ }^{\circ} \mathrm{C}\right)$ with a heating rate of $7^{\circ} \mathrm{C} / \mathrm{min}$ and then kept for $15 \mathrm{~min}$. Real-time surface temperatures were measured by the infrared thermometer pre-installed in apparatuses, i.e. following temperatures represented the surface temperatures except for special description. For the cooling treatment, the power was turn off and the specimen was allowed with a slow cooling rate to simulate the cooling of surrounding rocks.

\section{Specimen preparation}

Considering the complete penetration of microwaves and the cavity dimension of microwave oven, the granite was cut and polished as a cube of $20 \mathrm{~mm}$ by using a disk sawing machine. The internal structure variability from one specimen to next due to the grain size was attenuated by multiple tests. Specimens with distinct cracks were discarded to avoid the influence of initial macro-cracking. Furthermore, all specimens were cleaned and dried at $110{ }^{\circ} \mathrm{C}$ for $12 \mathrm{~h}$ in a conventional drying oven in order to eliminate the influence of moisture.

\section{Uniaxial compressive strength testing}

Uniaxial compressive strength (UCS) testing was performed on heated specimens using a compression testing machine (TYE-300) with a maximum load of $300 \mathrm{kN}$. For all testing, a load rate of $0.3 \mathrm{kN} / \mathrm{s}$ was adopted to fail the specimen and 
the uniaxial compressive strength was measured by the data acquisition system. The fragments of each specimen were collected for the subsequent characterization and the testing rig was then cleaned in order to avoid the samples mixing.

\section{Characterization}

TG/DSC analysis was carried on a thermogravimetric and differential scanning calorimetry synchronous analyzer (SDT Q160, TA Instruments) with a heating rate of $10^{\circ} \mathrm{C} / \mathrm{min}$ under air atmosphere for obtaining temperature-dependent characteristics of the granite. A scanning electronic microscope (EM8000F, KYKY) was employed to observe the microtopography of fragment surface after uniaxial compressive strength testing. The fragments were glued to conductive resin and sprayed with golden powders before testing. The mineral phases before and after heating treatments were confirmed by the powder X-ray diffraction (XRD, RINT) with $\mathrm{Cu} \mathrm{K} \alpha$ radiation $(\lambda=1.54184 \AA$ ). The XRD pattern was recorded at $2 \theta$ from $3^{\circ}$ to $80^{\circ}$ with a scanning rate of $8 \% \mathrm{~min}$. Before TG/DSC and XRD testing, the powders in each group were mixed uniformly with absolute ethanol and milled in the agate mortar, and subsequently dried in drying oven.

\section{RESULTS AND DISCUSSION}

\section{Morphologies}

$\Lambda$ fter heating treatments, specimens were carefully inspected to identify the change of morphologies, as shown in Fig. 2 and Fig. 3. The color in two groups changed from gray-apricot to white-jacinth as temperature increased, but the color change in group A was more distinct at the same temperature. In particular, the further color change of specimen in group A, from white-jacinth to white-brown, was observed for the molten area at $1000{ }^{\circ} \mathrm{C}$. The change in color of rock, which is mainly attributed to the mineralogy variation at specific temperatures, generally represents the thermal damage degree of rock. Thus, it preliminarily indicates that the deterioration of rock region directly irradiated by microwaves is serious than the area heated by thermal transfer at the same temperature.

Next, from the macro-cracking initiation, the deterioration of specimen in group $\mathrm{A}$ is also more serious than the specimen in group B at the same temperature. Visible macro-cracks appeared when the temperature reached $900{ }^{\circ} \mathrm{C}$ in group A but until $1000{ }^{\circ} \mathrm{C}$ in group B. These cracks cross over the quartz and feldspar grains and connected together with biotite as the node, probably linked to the thermal mismatch and thermal-induced stress concentration [21,23]. In addition, a detached cleavage plane locating at the cubic edge is observed at $800^{\circ} \mathrm{C}$ in group $\mathrm{B}$, which belongs to feldspar considering the absence of cleavage in quartz. Moreover, a fractured cubic edge is found at $900{ }^{\circ} \mathrm{C}$ (Fig. 4 (g)), which is also caused by thermalinduced stress concentration. The cracking propagation illustrates that the heat energy required for cleavage plane failure is lower than the consumption for generating macro-cracks at surface. It further reveals that the cleavage and surface edge are the vulnerable positions of rock mass exposed to high temperatures.
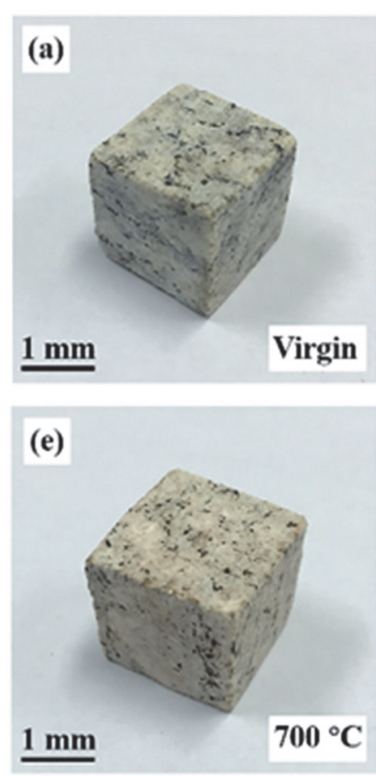
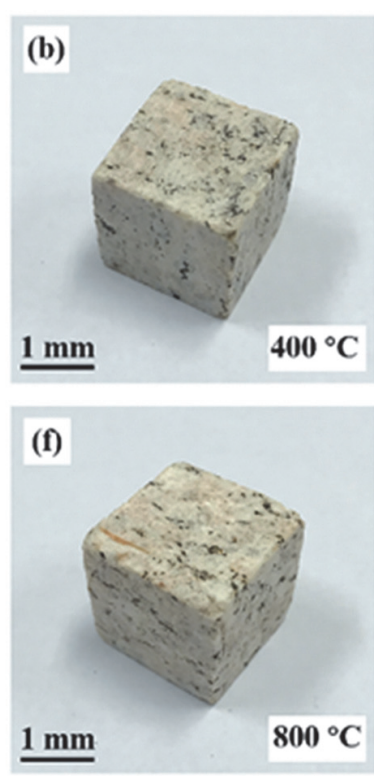
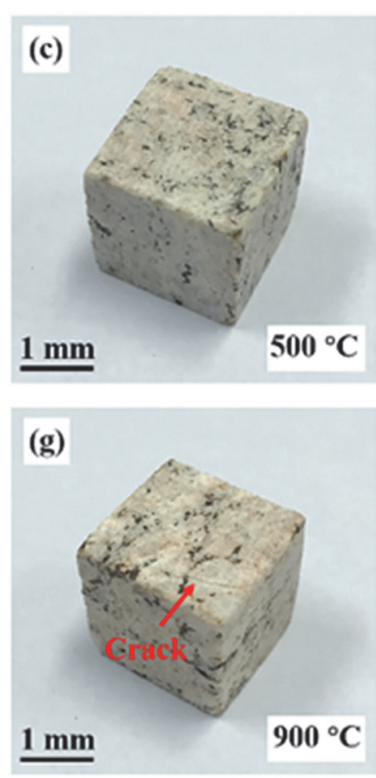
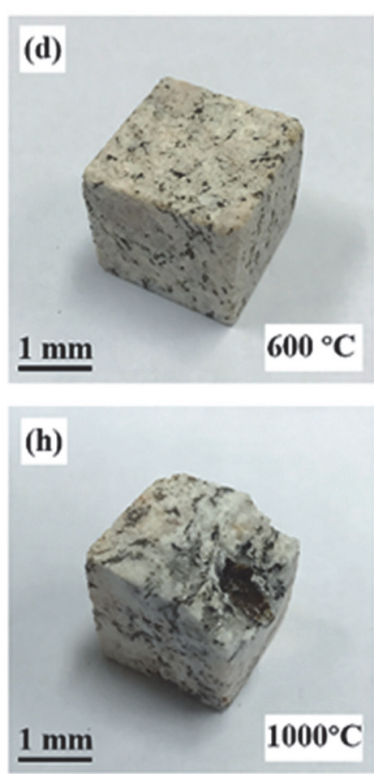

Figure 2: Morphologies of specimens before and after microwave irradiation. 

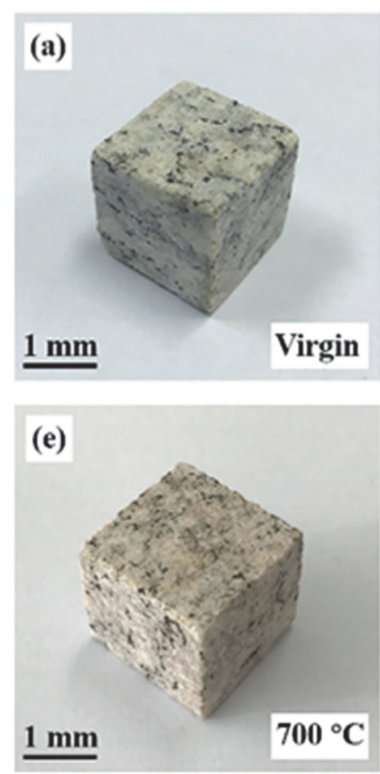
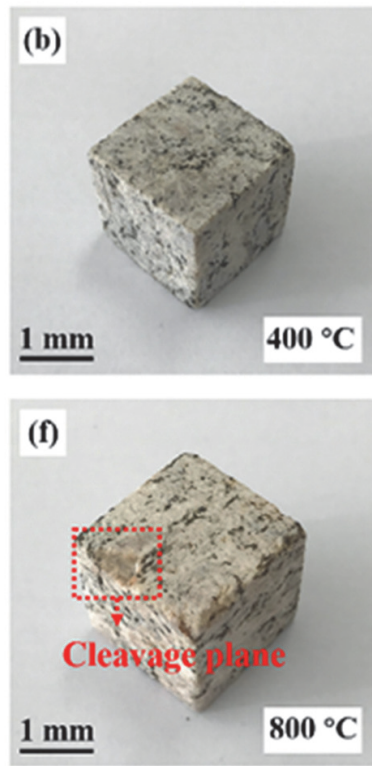
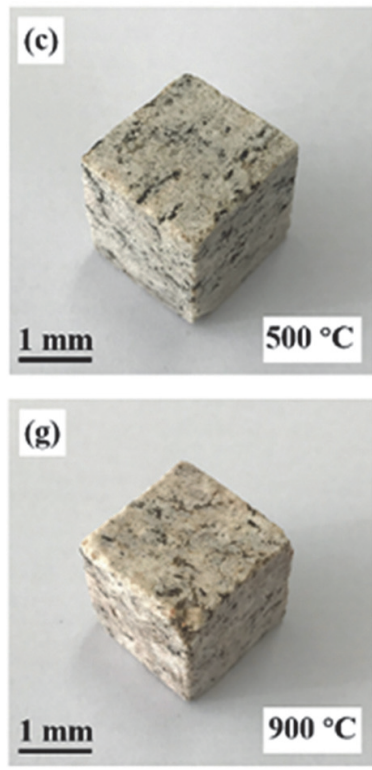

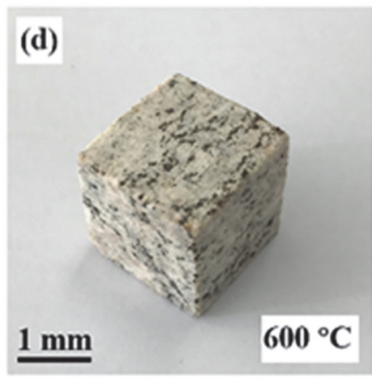

(h)

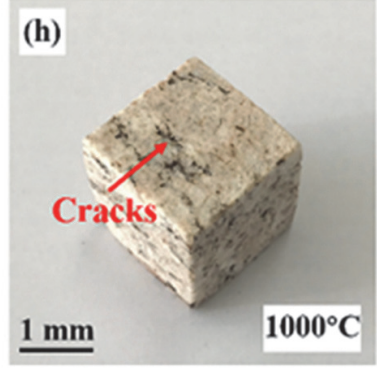

Figure 3: Morphologies of specimens before and after resistance-heating treatment

$T G / D S C$

TG/DSC analysis enables identifying of temperature-dependent characteristics of the granite. The TG and DSC curves are given on the common figure (Fig. 4). The TG curve shows the variation of mass as a function of temperature, and the DSC curve shows the amount of heat applied as a function of temperature.

In course of the run, the maximum mass loss of approximately $0.21 \%$ is detected at $664{ }^{\circ} \mathrm{C}$, which is visible on the TG curve. This might be attributed to the multiple processes of water loss as temperature increased. The evaporation of free water takes up $0.06 \%$ and the most of rest $(0.15 \%)$ is possibly related to the mineralogical variation. Seeing the wide endothermic band around $300{ }^{\circ} \mathrm{C}$, it is perhaps induced by the iron mineral transition, e.g. the decomposition of goethite to form haematite at $300{ }^{\circ} \mathrm{C}$ [24]. Besides, it also can be due to pyrolysis of the organic matter. The slope variation on the TG curve for temperature between $350^{\circ} \mathrm{C}$ and $400{ }^{\circ} \mathrm{C}$, probably express the accomplishment of organic reaction. However, the specific reaction cannot be confirmed due to the complex composition of granite. For the temperature in excess of 400 ${ }^{\circ} \mathrm{C}$, the dehydration and further dehydroxylation of biotite probably results in the further mass decline according to Labus and Lempart [25]. For temperature greater than $664^{\circ} \mathrm{C}$, the re-increase of TG curve may be due to the oxidation of some minerals in air atmosphere. In addition, the small endothermic peak representing $\alpha-\beta$ quartz phase transition at $573{ }^{\circ} \mathrm{C}$ is detected [19], which is visible on the DSC curve. This transition is accompanied by approximately $5 \%$ of volume expansion which can induce numerous micro-cracks around the grain of quartz [26].

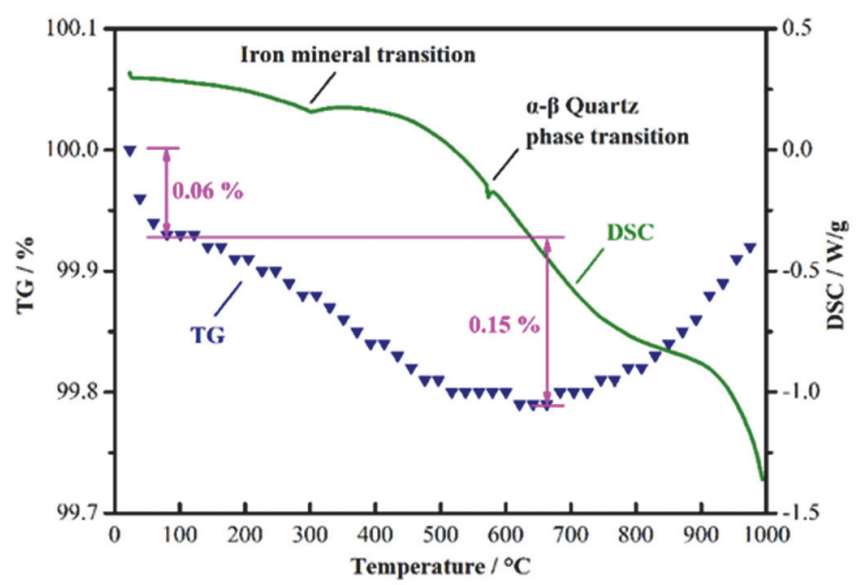

Figure 4: TG-DSC patterns obtained from Danfeng granite 
UCS

Fig. 5 shows the UCS of 42 specimens after two heating treatments. A similar variation pattern can be defined with temperature ranging from $400{ }^{\circ} \mathrm{C}$ to $900{ }^{\circ} \mathrm{C}$, which is the initial strengthening, subsequent weakening and final stabilizing. In this range of temperature, the maximum decline in group $\mathrm{A}$ is about $20 \%$ around $700{ }^{\circ} \mathrm{C}$, whereas about $10 \%$ is displayed in group B. Over $900{ }^{\circ} \mathrm{C}$, the group A presents a second decrease by approximately $70 \%$ than untreated specimen, whereas the group $\mathrm{B}$ exhibits almost unchanged.

The growth observed for the temperature less than $500{ }^{\circ} \mathrm{C}$, so called the thermal-induced strengthening, may be due to the strain hardening by localized transition plasticity development [27]. It is accommodated by changes in mineral decomposition/growth or monomineralic phase transitions. Here, the strengthening less than $500{ }^{\circ} \mathrm{C}$ is related to the iron mineral transition, which is reflected as the wide endothermic peak at $300{ }^{\circ} \mathrm{C}$ on the DSC curve. Noted that the uniaxial compressive strength testing was conducted after the cooling treatment, i.e. the strengthening on rock by localized transition plasticity was irreversible. Moreover, the strengthening is also related to mineral expansion which narrowed the cracks or pores to improve the integrity of granite. When temperature came to the next threshold, the transition of $\alpha-\beta$ quartz at 573 ${ }^{\circ} \mathrm{C}$, numerous micro-cracks generated due to the compression of expanded quartz grain, inducing the weakening of granite structure. The quartz is considered as significantly affecting the mechanical performance of granite, however, the average decrease between $573{ }^{\circ} \mathrm{C}$ and $900{ }^{\circ} \mathrm{C}$ is only about $10 \mathrm{MPa}$ in two groups, perhaps due to the not much content of quartz in the granite [28]. In third stage, combined with the TG/DSC results, the initiation of stabilizing stage corresponds to the ending of mass loss, which proves the importance of water loss on damaging the rock structure exposed to high temperature. The plateau also illustrates that if the further reduction of mechanical strength is expected, the much more heat energy will be required, as given in the group A at $1000^{\circ} \mathrm{C}$. See the partial melting of the specimen in group A at $1000{ }^{\circ} \mathrm{C}$, the internal maximum temperature definitely exceeded the measured surface temperature. The distinct deterioration is most likely attributed to that melting destroyed the original crystal-mineral framework of granite.

The contrast in two groups was also discussed in detail. In strengthening and weakening stage, the UCS of group A is lower than group $\mathrm{B}$ by approximately $20 \mathrm{MPa}$ and $10 \mathrm{MPa}$ respectively. It means that temperature-controlled microwave irradiation can reduce the strengthening due to localized transition plasticity and further promote the rock structure to deteriorate in weakening stage. It is beneficial to ensure the stability of surrounding rocks that the strength of directly irradiated zone is lower than surrounding rocks at the same temperature. Next, the standard deviation (SD) in the two groups show the difference of granite deterioration at the same temperature under the two heating treatments. Considering the short time of thermal preservation, the biggish deviation for temperature less than $600{ }^{\circ} \mathrm{C}$ is firstly related to uneven heating. For the temperature in excess of $600{ }^{\circ} \mathrm{C}$, contrary to the small variability of group $\mathrm{A}$, the group $\mathrm{B}$ still shows greater dispersion. This variation not only illustrates uniform heating of microwave irradiation on the rock at high temperatures, but also reveals the mechanical performance of rock exposed to high temperature induced by microwave irradiation is more accurately to forecast. Certainly, the variability of mineral composition/distribution from the one specimen to the next should not be ignored. All of these variabilities can influence the manner by which the damaging conditions of rock exposed to microwave irradiation in a practical engineering. Before excavation, a comprehensive mineralogical investigation for the target rock mass and the irradiation testing in a broad range of temperature on samples should not be absence. Ideally, microwaves can be employed to irradiate the vulnerable positions (e.g. cleavage plane and surface edge) and kept the whole rock mass being heated up to $600{ }^{\circ} \mathrm{C}$, instead of irradiating the whole rock mass or heating it up to very high temperatures (seeing the plateau at $\mathrm{T}=600-900^{\circ} \mathrm{C}$ ), so as to preserve the original intention of reducing energy consumption.
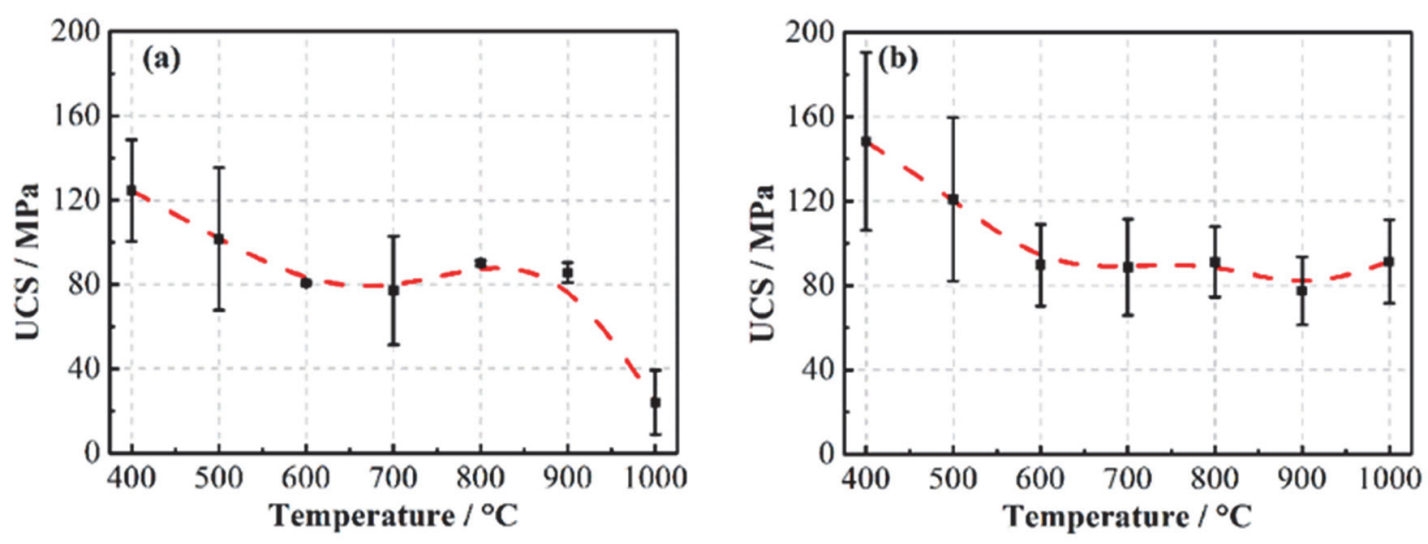

Figure 5: The UCS of specimens after heating treatments: (a) microwave irradiation group and (b) resistance-heating group. 
SEM

SEM provides a convenient path to observe the fracture surface of original and treated specimens after UCS testing, as given in the Fig. 6. The number and dimension of cracks significantly increased with temperature increasing. Those were also found the internal cracks of biotite and a radially oriented fracture which originated from the biotite (see in Fig. 6 (g)). Besides, the shape of fracturing edge at low temperatures exhibited sharp. However, the sharpness declined with temperature increasing. In addition, specimens at high temperatures were destroyed accompanying with remarkable powdering during the UCS testing. These might be due to the numerous interlaced micro-cracks observed nearby the fracturing edge, seeing in Fig. 6 (f). Moreover, Fig. 6 (d) indicated that molten minerals formed the glass substance with numerous pores and bubbles. It is apparent that the strength of glass structure is far less than the original crystal framework, inducing the distinct decrease of UCS in group A at $1000^{\circ} \mathrm{C}$.
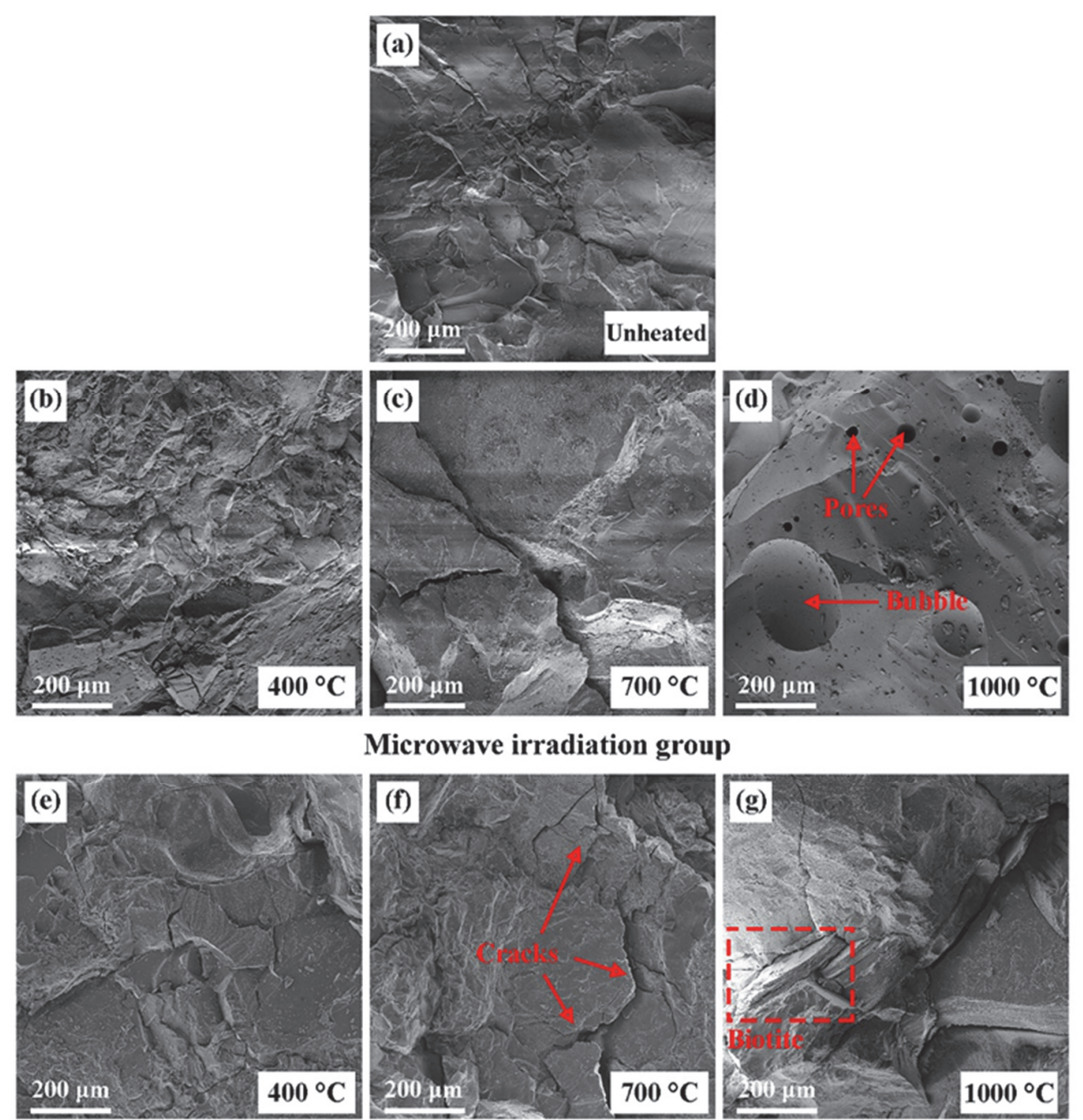

Resistance-heating group

Figure 6: SEM images of fracture surface after uniaxial compressive strength testing

$X R D$

The XRD analysis enables obtaining of mineral phases variation before and after the two heating treatments (Fig. 7). The mineral composition exhibited unchangeableness after both heating treatments, but the variation of mineral crystal structures can be detected. The phase of quartz in two groups exhibit unchangeableness even at $1000{ }^{\circ} \mathrm{C}$. However, diffraction peaks of both biotite and feldspar in group A vanished at $1000{ }^{\circ} \mathrm{C}$ due to amorphization. The powders were obtained from molten areas and mixed uniformly, which could eliminate the variability of components. Therefore, the glass substance observed in Fig. 6 (d) was mainly composed of feldspar and biotite. It also can be inferred that the maximum temperature was below the melting point of quartz. Besides, it also found in group A that the diffraction peak intensity of 
K-feldspar at $2 \theta=27.4^{\circ}$ decreased while the diffraction peak intensity of plagioclase at $2 \theta=28.0^{\circ}$ increased with increasing temperature.

To further interpret the variation, the full width at half maximum (FWHM) of K-feldspar at $2 \theta=27.4^{\circ}$ and plagioclase at $2 \theta=28.0^{\circ}$ in two groups as temperature increased were calculated, as shown in Fig. 8. The FWHM variation of group A is consistent with the corresponding UCS data. However, the group B exhibits nothing similar to the phenomenon. It indicated that the microwave irradiation affected the mechanical performance of rock by leading a similar and irreversible variation on crystal structures of $\mathrm{K}$-feldspar and plagioclase, and this affair significantly contributed to the mechanical performance variation of granite irradiated by microwaves. In particular, the plagioclase expresses a more intense response to microwave irradiation than $\mathrm{K}$-feldspar. To meet the practical application, analysing the plagioclase crystallinities at different temperatures possibly can be used as guide to preliminarily estimate the structural deterioration of granite irradiated by microwaves before carrying out the time-consuming mechanical performance tests.
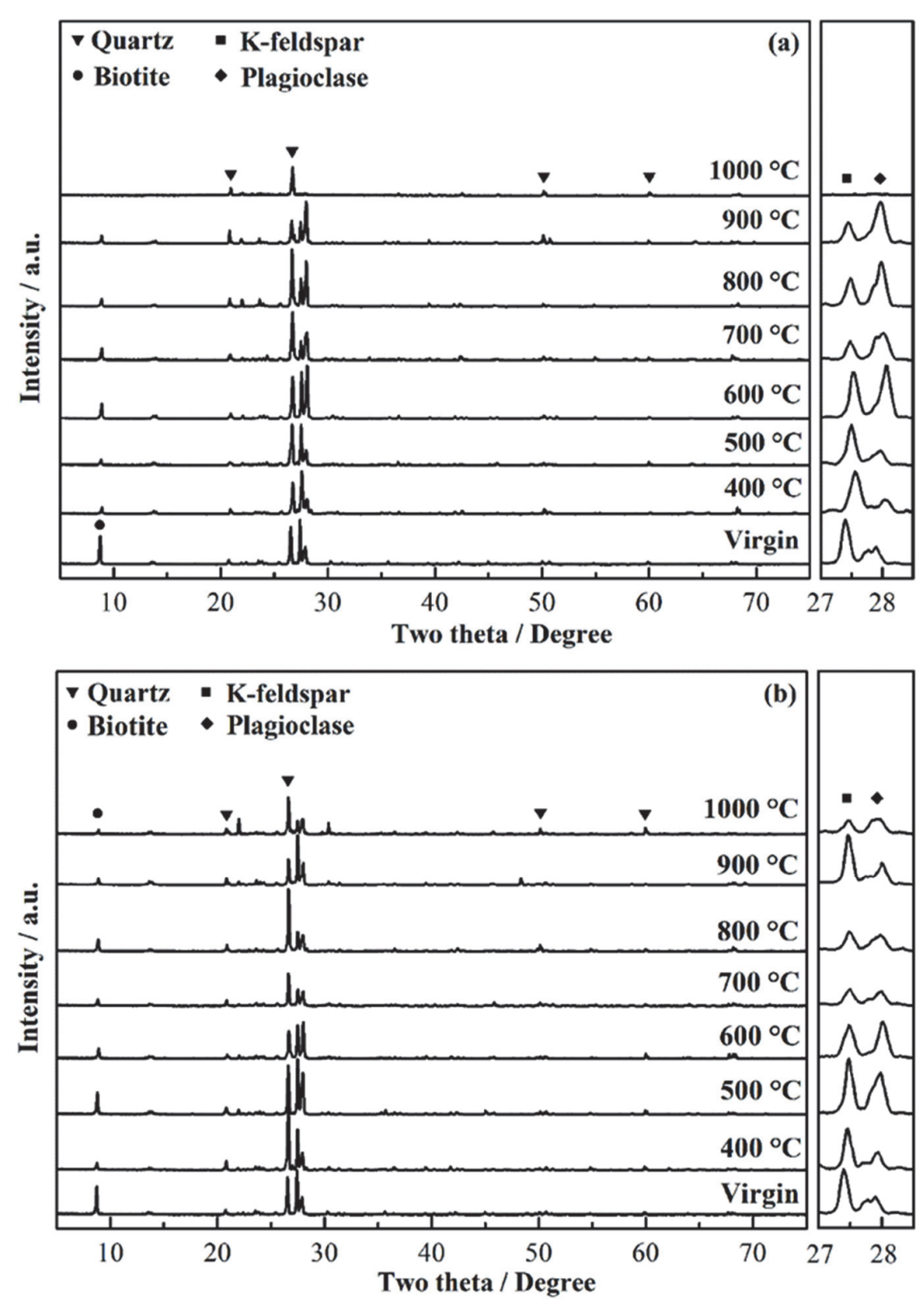

Figure 7: XRD patterns of granite powders before and after heating treatments: (a) microwave irradiation group and (b) resistanceheating group. 

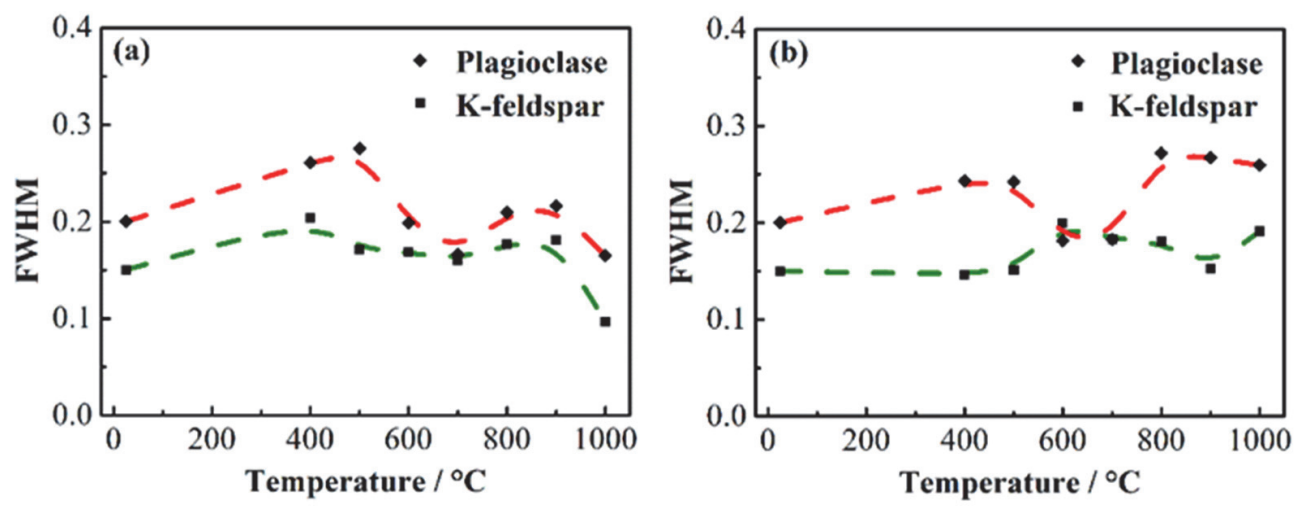

Figure 8: FWHM vs. temperature of K-feldspar at $2 \theta=27.4^{\circ}$ and plagioclase at $2 \theta=28.0^{\circ}$ : (a) microwave irradiation group and (b) resistance-heating group.

\section{CONCLUSIONS}

comparative study is presented for investigating the deterioration difference of granite between directly heated by microwave irradiation and indirectly heated by heat transfer. Danfeng granite specimens were heated up to $400-$ $11000^{\circ} \mathrm{C}$ and then kept for $15 \mathrm{~min}$ by using the microwave irradiation and resistance-heating treatment, respectively. From the experimental investigations, the following conclusions can be drawn:

(1) UCS results detect that there is a similar variation in two groups between $400{ }^{\circ} \mathrm{C}$ and $900{ }^{\circ} \mathrm{C}$, which is initial strengthening (less than $500^{\circ} \mathrm{C}$ ), subsequent weakening $\left(500-600^{\circ} \mathrm{C}\right.$ ) and final stabilizing $\left(600-900^{\circ} \mathrm{C}\right)$. In this range of temperature, the group $\mathrm{A}$ is lower than group $\mathrm{B}$ by approximately $20 \mathrm{MPa}$ and $10 \mathrm{MPa}$ respectively. The maximum reduction in group $\mathrm{A}$ is about $20 \%$ around $600-700{ }^{\circ} \mathrm{C}$, whereas about $10 \%$ is displayed in group B at the same temperature. When temperature reached $1000^{\circ} \mathrm{C}$, group A presents a second reduction accompanied by partial melting while the group B is almost unchanged.

(2) From the TG/DSC and XRD results, the strengthening below $500{ }^{\circ} \mathrm{C}$ is perhaps related to the transition of iron minerals at $300{ }^{\circ} \mathrm{C}$. SEM and XRD results reveal that the feldspar and biotite melted and formed the deficient porous glass substance, resulting in the second decline at $1000{ }^{\circ} \mathrm{C}$. Furthermore, temperature-controlled microwave irradiation was found to lead a similar and irreversible variation on feldspar FWHM, which is consistent with the corresponding UCS data. Especially plagioclase is more sensitive to microwave irradiation than K-feldspar, which means the FWHM of plagioclase can be used as a guide to pre-estimate the deterioration of granite irradiated by microwaves before carrying out mechanical performance testing.

(3) Microwave irradiation is beneficial to ensure the stability of surrounding rocks by reducing the strengthening due to localized transition plasticity and further promotes the deterioration of rock structure in weakening stage. To meet the practical engineering, authors proposed employing microwave to irradiate the vulnerable positions (surface edge and cleavage) and kept the whole rock mass being heated up to $600{ }^{\circ} \mathrm{C}$. Besides, the non-uniform heating and structural variability are detected which significantly affect the deterioration of granite exposed to heating treatments. Further research will be focused on quantizing these influences.

\section{ACKNOWLEDGEMENTS}

$\mathrm{T}$ his research was supported by the National Natural Science Foundation of China (21677118). The authors would like to express sincere gratitude to Lanjie Hou of Key Laboratory of Solid Waste Treatment and Resource Recycle, Ministry of Education for the help in rock mineralogical analysis.

\section{REFERENCES}

[1] Hassani, F., P. M. Nekoovaght, and N. Gharib. (2016). The influence of microwave irradiation on rocks for microwaveassisted underground excavation. J. Rock. Mech. Geotech. Eng. 8(1), pp. 1-15. DOI: 10.1016/j.jrmge.2015.10.004. 
[2] Fan, L. F., Z. J. Wu, Z. Wan, and J. W. Gao. (2017). Experimental investigation of thermal effects on dynamic behavior of granite. Appl. Therm. Eng. 125(2017), pp. 94-103. DOI: 10.1016/j.applthermaleng.2017.07.007

[3] Becattini, V., T. Motmans, A. Zappone, C. Madonna, A. Haselbacher, and A. Steinfeld. (2017). Experimental investigation of the thermal and mechanical stability of rocks for high-temperature thermal-energy storage. Appl. Energ. 203(2017), pp. 373-389. DOI: 10.1016/j.apenergy.2017.06.025.

[4] Hartlieb, P., and S. Bock. (2017). Theoretical Investigations on the Influence of Artificially Altered Rock Mass Properties on Mechanical Excavation. Rock. Mech. Rock. Eng. 11(2017), pp. 1-9. DOI: 10.1007/s00603-017-1355-3.

[5] Zheng, Y. L., Q. B. Zhang, and J. Zhao. (2017). Effect of microwave treatment on thermal and ultrasonic properties of gabbro. Appl. Therm. Eng. 127(2017), pp. 359-369. DOI: 10.1016/j.applthermaleng.2017.08.060.

[6] Satish, H., J. Ouellet, V. Raghavan, and P. Radziszewski. (2013). Investigating microwave assisted rock breakage for possible space mining applications. Min. Technol. 115(1), pp. 34-40. DOI: 10.1179 / 174328606X101902.

[7] Meisels, R., M. Toifl, P. Hartlieb, F. Kuchar, and T. Antretter. (2015). Microwave propagation and absorption and its thermo-mechanical consequences in heterogeneous rocks. Int. J. Miner. Process. 135(2015), pp. 40-51.

DOI: $10.1016 /$ j.minpro.2015.01.003.

[8] Nelson, S., D. Lindroth, and R. Blake. (1989). Dielectric Properties of Selected and Purified Minerals at 1 to 22 GHz. J. Microwave. Power. 24(4), pp. 213-220. DOI: 10.1080/08327823.1989.11688096.

[9] Ulaby, F. T., T. H. Bengal, M. C. Dobson, J. R. East, J. B. Garvin, and D. L. Evans. (1990). Microwave dielectric properties of dry rocks. Ieee. T. Geosci. Remote. 28(3), pp. 325-336. DOI: 10.1109/36.54359.

[10] Lu, G. M., Y. H. Li, F. Hassani, and X. Zhang. (2017). The influence of microwave irradiation on thermal properties of main rock-forming minerals. Appl. Therm. Eng. 112(2017), pp. 1523-1532.

DOI: $10.1016 /$ j.applthermaleng.2016.11.015.

[11] Toifl, M., R. Meisels, P. Hartlieb, F. Kuchar, and T. Antretter. (2015). 3D numerical study on microwave induced stresses in inhomogeneous hard rocks. Miner. Eng. 90(2015), pp. 29-42. DOI: 10.1016/j.mineng.2016.01.001

[12] Batchelor, A. R., A.J. Buttress, D. A. Jones, J. Katrib, D. Way, T. Chenje, D. Stoll, C. Dodds, and S. W. Kingman. (2017). Towards large scale microwave treatment of ores: Part 2-Metallurgical testing. Miner. Eng. 111(2017), pp. 5-24. DOI: 10.1016/j.mineng.2017.05.003

[13] Hartlieb, P., F. Kuchar, P. Moser, H. Kargl, and U. Restner. (2018). Reaction of different rock types to low-power (3.2 $\mathrm{kW}$ ) microwave irradiation in a multimode cavity. Miner. Eng. 118(2018), pp. 37-51.

DOI: $10.1016 /$ j.mineng.2018.01.003

[14] Toifl, M., P. Hartlieb, R. Meisels, T. Antretter, and F. Kuchar. (2016). Numerical study of the influence of irradiation parameters on the microwave-induced stresses in granite. Miner. Eng. 103-104(2016), pp. 78-92.

DOI: 10.1016/j.mineng.2016.09.011

[15] Yang, S. Q., P. G. Ranjith, H. W. Jing, W. L. Tian, and Y. Ju. (2017). An experimental investigation on thermal damage and failure mechanical behavior of granite after exposure to different high temperature treatments. Geothermics. 65(2017), pp. 180-197. DOI: 10.1016/j.geothermics.2016.09.008

[16] Zhang, Y., Q. Sun, and J. Geng. (2017). Microstructural characterization of limestone exposed to heat with XRD, SEM and TG-DSC. Mater. Charact. 134(2017), pp. 285-295. DOI: 10.1016/j.matchar.2017.11.007

[17] Zhang, W., Q. Sun, S. Zhu, and B. Wang. (2017). Experimental study on mechanical and porous characteristics of limestone affected by high temperature. Appl. Therm. Eng. 110(2017), pp. 356-362. DOI: $10.1016 /$ j.applthermaleng.2016.08.194.

[18] Sirdesai, N. N., T. N. Singh, and R. P. Gamage. (2017). Thermal alterations in the poro-mechanical characteristic of an Indian sandstone-A comparative study. Eng. Geol. 226(2017), pp. 208-220. DOI: 10.1016/j.enggeo.2017.06.010.

[19] Plevova, E., L. Vaculikova, A. Kozusnikova, M. Ritz, and G. S. Martynkova. (2016). Thermal expansion behaviour of granites. J. Therm. Anal. Calorim. 123(2), pp. 1555-1561. DOI: 10.1007/s10973-015-4996-z.

[20] Tiskatine, R., A. Eddemani, L. Gourdo, B. Abnay, A. Ihlal, A. Aharoune, and L. Bouirden. (2016). Experimental evaluation of thermo-mechanical performances of candidate rocks for use in high temperature thermal storage. Appl. Energ. 171(2016), pp. 243-255. DOI: 10.1016/j.apenergy.2016.03.061.

[21] Zhu, S., W. Zhang, Q. Sun, S. Deng, J. Geng, and C. Li. (2017). Thermally induced variation of primary wave velocity in granite from Yantai: Experimental and modeling results. Int. J. Therm. Sci. 114(2017), pp. 320-326.

DOI: 10.1016/j.ijthermalsci.2017.01.008.

[22] Zuo, J. P., J. T. Wang, Y. J. Sun, Y. Chen, G. H. Jiang, and Y. H. Li. (2017). Effects of thermal treatment on fracture characteristics of granite from Beishan, a possible high-level radioactive waste disposal site in China. Eng. Fract. Mech. 182(2017), pp. 425-437. DOI: 10.1016/j.engfracmech.2017.04.043. 
[23] Ali, A. Y., and S. M. Bradshaw. (2010). Bonded-particle modelling of microwave-induced damage in ore particles. Miner. Eng. 23 (10), pp. 780-790. DOI: 10.1016/j.mineng.2010.05.019.

[24] Goss, C. J. (1987). The Kinetics and Reaction Mechanism of the Goethite to Hematite Transformation. Mineral. Mag. 51(361), pp. 437-451. DOI: 10.1180/minmag.1987.051.361.11.

[25] Labus, M., and M. Lempart. (2018). Studies of Polish Paleozoic shale rocks using FTIR and TG/DSC methods. J. Petrol. Sci. Eng. 161(2018), pp. 311-318.DOI: 10.1016/j.petrol.2017.11.057.

[26] Chen, S., C. Yang, and G. Wang. (2017). Evolution of thermal damage and permeability of Beishan granite. Appl. Therm. Eng. 110(2017), pp. 1533-1542. DOI: 10.1016/j.applthermaleng.2016.09.075.

[27] Ranjith, P. G., D. R. Viete, B. J. Chen, and M. S. A. Perera. (2012). Transition plasticity and the effect of temperature on the mechanical behaviour of Hawkesbury sandstone at atmospheric pressure. Eng. Geo. 151(151), pp. 120-127. DOI: 10.1016/j.enggeo.2012.09.007.

[28] Chen, Y. L., S. R. Wang, J. Ni, R. Azzam, and T. M. Fernández-Steeser. (2017). An experimental study of the mechanical properties of granite after high temperature exposure based on mineral characteristics. Eng. Geol. 220(2017), pp. 234242. DOI: $10.1016 /$ j.enggeo.2017.02.010. 